\title{
효율적인 $\mathrm{SoC}$ 논리합성을 위한 혼합방식의 설계 방법론
}

\author{
서영호* · 김동욱** \\ Efficient Design Methodology based on Hybrid Logic Synthesis for SoC \\ Young-ho Seo* · Dong-wook Kim**
}

이 논문은 2011년도 정부(교육과학기술부)의 재원으로 한국연구재단의 지원을 받아

수행된 기초연구사업임(NRF-2010-0013468).

\section{요 약}

본 논문에서는 크게 두 가지 사항에 대해서 제안하고자 한다. 첫 번째는 논리합성을 위한 제약조건 방법에 대한 것이고, 두 번째는 효율적인 논리합성방법에 대한 것이다. 논리 합성은 주어진 제약조건(constraint)을 최대한 만족 시키면서 논리 사상과 최적화 등을 통하여 RTL(register transfer level) 코드로부터 게이트-수준의 네트리스트를 얻 는 과정이다. 논리합성의 결과는 주어진 제약조건과 합성 방법에 매우 종속적이다. 이들에 의해서 설계의 면적 및 타이밍이 크게 변화하므로 우리는 제약조건과 합성방법을 철저하게 고려하여야 한다. 본 논문에서는 논리합성을 하는 과정에서 실제로 고려해야하는 사항들에 대해서 경험적이고 실험적인 결과를 바탕으로 혼합방식의 논리합성 기법을 제안한다. 제안된 기법을 이용하여 약 65 만 게이트의 하드웨어 자원량을 사용하는 회로에 적용시켜본 결과 로 상향식 방법에 비해서 합성 시간이 약 $47 \%$ 감소하였고, 하향식 방법에 비해서 타이밍 특성이 우수하였다.

\section{ABSTRACT}

In this paper, we propose two main points. The first is the constraint for logic synthesis, and the second is an efficient logic synthesis method. Logic synthesis is a process to obtain the gate-level netlist from RTL (register transfer level) codes using logic mapping and optimization with the specified constraints. The result of logic synthesis is tightly dependent on constraint and logic synthesis method. Since the size and timing can be dramatically changed by these, we should precisely consider them. In this paper, we present the considering items in the process of logic synthesis by using our experience and experimental results. The proposed techniques was applied to a circuit with the hardware resource of about $650 \mathrm{~K}$ gates. The synthesis time for the hybrid method was reduced by $47 \%$ comparing the bottom-up method and It has better timing property about slack than top-down method.

$$
\text { 키워드 }
$$

논리합성, $\mathrm{SoC}$, 칩, 최적화, $\mathrm{CTS}$, 제약조건, 하향식, 상향식

Key word

logic synthesis, SoC, chip, optimization, CTS, constraint, top-down, bottom-up

* 종신회원 : 광운대학교

** 종신회원 : 광운대학교 (교신저자, dwkim@kw.ac.kr)
접수일자 : 2011, 10, 17

심사완료일자 : 2011. 12. 20

\section{Open Access http://dx.doi.org/10.6109/jkiice.2012.16.3.571}

(c)This is an Open Access article distributed under the terms of the Creative Commons Attribution Non-Commercial License(http://creativecommons.org/li-censes/by-nc/3.0/) which permits unrestricted non-commercial use, distribution, and reproduction in any medium, provided the original work is properly cited. 


\section{I. 서 론}

논리합성은 George Boole에 의해 논리라는 것이 다루 어진 때부터 시작한다. 1938년에 Claude Shannon은 2-레 벨 부울 대수가 스위칭 회로의 동작을 나타낼 수 있다는 것을 증명하였다. 지금도 많이 활용되지만 초창기의 논 리 설계는 카르노 맵을 이용해서 진리표를 최적화시키 는 것이었다[1][2]. 그러나 카르노 맵을 이용한 논리 회 로 설계는 6 개 이상의 변수가 사용될 경우에 사람이 직 접 수행하기는 거의 불가능하였다.

논리 최소화를 자동화한 첫 번째 사례는 QuineMcCluskey 알고리즘을 컴퓨터로 구현한 것이었다. 최근 에는 Espresso heuristic logic minimizer가 논리 최소화를 위한 표준 도구가 되었다[3][4]. 초창기 연구의 또 다른 영역은 유한상태기계(finite state machine, FSM)의 상태 를 최소화하고 인코딩하는 것이었다. 논리 합성을 위한 응용분야는 주로 디지털 컴퓨터를 설계하는 것에 초점 이 맞추어져 있었기 때문에 IBM과 Bell 연구소는 논리 합성의 자동화에 선구자와 같은 역할을 수행하였다[5]. 이산 논리 소자들로부터 PLA (programmable logic array) 로의 발달은 효율적인 2-레벨 논리최소화의 필요성을 더욱 부각시켰다[6].

RTL 수준 혹은 행위 수준의 설계에서 대부분 회로의 표현은 다중 레벨로 되어 있다. 다중 레벨 회로를 설계하 는데 사용되어진 초창기 시스템은 IBM의 LSS(logical sub-system)이다. 이 시스템은 논리 간략화를 위해서 로 컬 변환기법을 사용하였다. LSS와 Yorktown Silicon Compiler를 이용한 작업은 1980 년 대에 논리합성 분야에 서 빠른 발전을 가져왔다. 대표적인 것이 버클리대의 SIS (strategic information system), 캘리포니아대의 RASP (random access stored program), 그리고 콜로라도대의 $\mathrm{BOLD}$ 이다. 최근에는 $\mathrm{CAD}$ (computer-added design) 개발 회사들에 의해서 개발이 주도되고 있다[7][8].

행위레벨에서 정의된 회로의 합성에 대한 연구에 의 해서 복잡한 ASIC이나 FPGA (field programmable gate array) 설계에 사용되는 상업적인 솔루션이 발달하게 되 었다. 오늘날 ESL (electronic system level) 합성과 행위적 레벨 합성으로 알려진 상위수준 합성은 본질적으로 ANSI C/C++ 혹은 System와 같은 상위수준의 언어로부 터 회로를 합성하는 것을 의미하고 있다. 반면에 논리 합
성은 구조적 혹은 함수적 표현을 RTL로 합성하는 것을 의미한다[9][10].

앞서서 논리 합성에 대한 정의와 과정을 설명하였는 데, 논리 합성의 사전적 의미는 중요하지 않다고 생각하 고, 본 논문에서는 논리 합성을 다음과 같이 정의한다. 논리 합성은 주어진 제약조건(constraint)을 최 대한 만족 시키면서 논리 사상과 최적화 등을 통하여 RTL 코드로 부터 게이트-수준의 네트리스트(netlist)를 얻는 과정이 다. 최적화는 RTL 코드 단계에서 이루어지는 것이 가장 효율적이다. 따라서 논리합성은 물리적 합성(physical implementation) 과정에서 가장 기본적이고 중요한 과정 이다. 논리합성의 결과는 주어진 제약조건과 합성 방법 에 매우 종속적이다. 이들에 의해서 설계의 면적 및 타이 밍이 크게 변화하므로 우리는 제약조건과 합성방법을 철저하게 고려하여야 한다. 아울러 제약조건을 매우 신 중히 작성할 수 있어야 한다.

본 논문에서는 크게 두 가지 사항에 대해서 논의하 고자 한다. 첫 번째는 성공적인 논리합성을 위한 제약 조건 방법에 대한 것이고, 두 번째는 합성방법에 대한 것이다. 본 논문에서는 논리합성을 하는 과정에서 실 제로 고려해야하는 사항들에 대해서 경험적이고 실험 적인 결과를 바탕으로 서술하고자 한다. 따라서 최신 의 고성능 $\mathrm{ASIC}$ 기반의 $\mathrm{SoC}$ 칩셋을 제작하고자 하는 엔지니어에 게 설계 기간을 단축하면서 고성능의 네트 리스트를 추출할 수 있는 설계 방법론을 제공하고자 한다.

본 논문은 다음과 같이 구성된다. 2 장에서는 성공적 인 논리합성을 위한 제약조건에 대해서 고려해야할 사 항들을 논의하고 3장에서는 합성 방법에 대해서 논의한 다. 이를 바탕으로 4 장에서는 논리합성 결과를 보이고, 5 장에서 결론을 맺는다.

\section{ㅍ. 제약조건}

본 장에서는 논리 합성 시 추출되는 네트리스트의 특성을 규정하기 위한 제약조건을 작성하는 데 있어서 고려해야되는 사항들을 논의한다. 논의를 함에 있어 서 Synopsys의 Design Compiler를 기준으로 설명을 전 개한다. 


\section{1. 클록의 선언}

클록은 설계의 가장 중요한 요소이다. 모든 타이밍 체 크 및 최적화는 선언된 클록을 기준으로 한다. 클록을 선 언하는 방법은 몇 가지가 있고, 이 때 반드시 클록 이름과 클록의 포트 이름이 같을 필요는 없다. MainClk를 Sub1Clk, Sub2Clk, Sub3Clk등으로 파생해서 사용하는 경우도 일반적이다. 이때 클록의 주기와 너비는 같다.

\section{2. 클록 불확실성}

셀들이 일정 셀 경계에 배치되면 그림 1 과 같이 클록 포트로부터 각각의 순차(sequential) 셀까지 클록 신호가 도달하는데 소요되는 지연시간이 각각 다르다. 따라서 그림 2 와 같은 데이터패스부가 존재할 때 이로 인한 타 이밍 문제는 그림 3 과 같이 발생한다.

논리합성 단계에는 셀들이 어떻게 배치되는지 알 수 없다. 따라서 각각의 순차 셀까지의 클록 지연시간을 판 단할 수 없다. CTS(clock tree synthesis)시에 클록 포트로 부터 각각의 순차 셀까지의 지연시간을 맞춰준다. 이 역 시 모든 순차 셀까지의 지연시간을 정확하게 맞출 수 없 으므로 $0.1 \mathrm{~ns} \sim 0.2 \mathrm{~ns}$ 범위내의 오차가 생긴다. 따라서 CTS 전 단계에서는 이런 오차를 고려하여 CTS가 되었 다고 가정한 후 CTS후의 이런 오차를 보정해주기 위한 개념이 클록 불확실성(uncertainty)이다.

그림 3에서 (1)의 $\mathrm{F} / \mathrm{F}$ 와 (2)의 $\mathrm{F} / \mathrm{F}$ 간 클록 지연시간차이 로 인해서 setup violation이 발생한다. 따라서 이들 간 지 연시간만큼 타이밍 여유를 갖고 합성을 진행해야 CTS 후에 setup violation을 막을 수 있다.

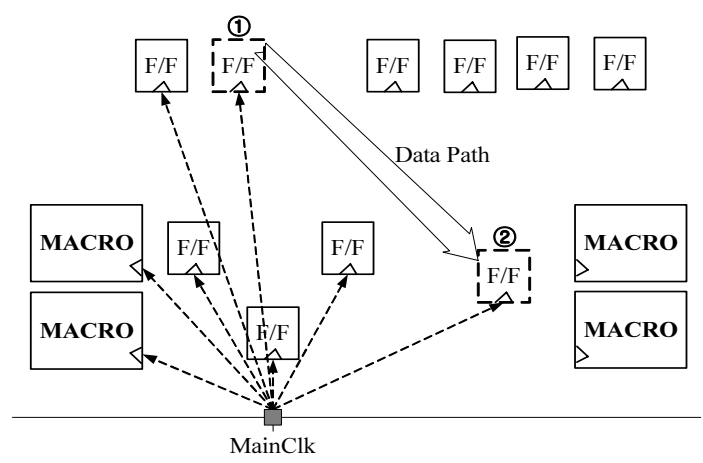

그림 1. CTS 이전

Fig. 1 Before CTS

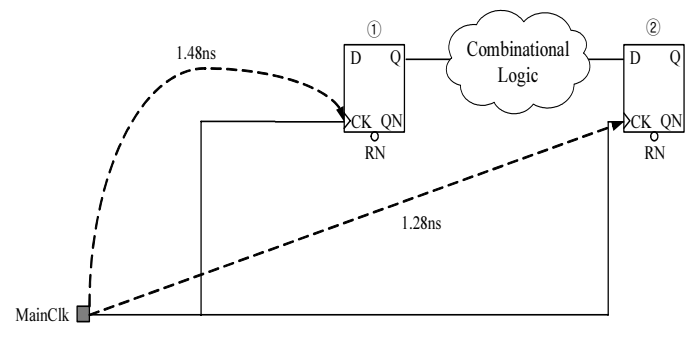

그림 2. 데이터 패스부

Fig. 2 Data path

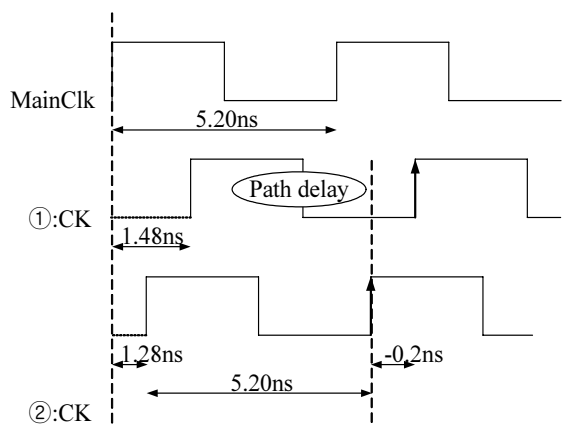

그림 3. 타이밍도

Fig. 3 Timing diagram

\section{3. 잘못된 경로}

실제로 데이터패스부는 존재하지만 논리 함수가 무 의미한 경로를 잘못된 경로(false path)라고 정의한다. 따 라서 잘못된 경로는 타이밍에 제약을 받지 않으며 최적 화가 되지 않는다. 이는 STA(static timing analysis)에서 타이밍 해석을 하지 않아도 되는 경로에 해당한다. 그림 4(a)에서 굵게 표시된 경로이다.

그림 4(a)에서 입력 $\mathrm{C}$ 로 입력되는 값이 언제나 1 이라 면 입력 $\mathrm{A}, \mathrm{B}$ 에서 출력 $\mathrm{D}$ 까지의 경로는 무의미 하며 최 적화가 필요 없다. 따라서 잘못된 경로로 선언할 수 있 다. 여러 개의 클록이 존재하는 설계에서는 상호 클록 간 에 관련이 있는지를 잘 따져봐야 한다. 잘못된 경로로 선 언되지 않은 두 개의 클록 영역에 데이터 경로가 존재한 다면 이들 주파수의 최소공배수에 맞춰서 합성하기 때 문이다. 그림 4(b)에서 조합회로 경로는 2 개의 클록 영역 에 노출되어 있다. Design compiler는 최소 공배수인 $600 \mathrm{MHz}$ 에 맞춰서 합성을 진행할 것이다. 그러나 $\mathrm{ACLK}$ 와 $\mathrm{BCLK}$ 는 동시에 입력될 수 없다. 
따라서 $\mathrm{ACLK}$ 와 $\mathrm{BCKL}$ 를 상호 잘못된 경로로 선언한 다면 제일 빠른 $200 \mathrm{MHz}$ 로 합성될 것이다.

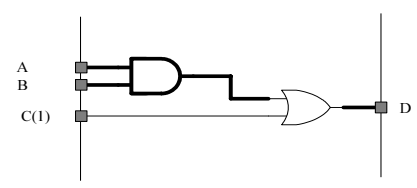

(a)

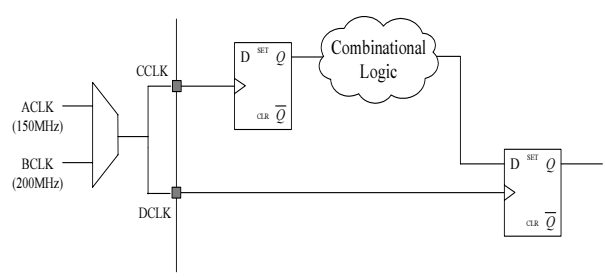

(b)

그림 4. 잘못된 경로 (a) 예제1, (b) 예제2

Fig. 4 False path; example (a) 1, (b) 2

\section{4. 입/출력 포트의 지연}

Design compiler는 자체 타이밍 검사 결과에 준해서 합성을 진행한다. 타이밍 검사는 순차 셀에서 다음 순차 셀까지의 데이터 경로를 검사한다. 그러나 최상위 설계 의 입력/출력 포트로부터의 경로는 순차 셀에서 시작되 는 경로가 아니므로 타이밍 검사를 할 수 없다. 따라서 이들 포트 외부에 순차 셀이 존재한다는 가정 하에 타이 밍 검사를 하게 된다. 이때 그림 5와 같이 가상의 외부 순 차 셀에서 이들 포트까지의 지연시간이 필요하다. 따라 서 설계자는 최상위 설계의 모든 포트에 대해서 가상의 지연시간을 지정해주어야 한다.

\section{5. 구동 셀}

설계 내부의 상황은 각 경로분석으로 알 수 있지만 외 부의 상황은 설계자가 직접 구축해야 한다. 현재 자신의 설계가 외부와 어떤 환경에서 연결하고 있는지는 설계 자만 알 수 있기 때문이다. 칩 외부에서 입력 포트로 어 느 정도의 구동력으로 신호가 전달되는지를 먼저 선언 해야 포트 근처의 버퍼 크기 및 삽입 여부를 알 수 있다. 입력 포트 외부에 가상의 셀을 두어 그 셀의 출력 포트로 부터의 신호가 입력 포트로 유입된다고 가정한다. 그리 고 그 세기를 외부 가상 셀의 출력 포트의 캐패시터값 으로 대변한다.
일반적으로 외부의 가상 셀은 매우 작은 출력 캐패시 터 값을 갖는 셀로 설정한다. 즉, 그림 6(a)는 그림 6(b)와 같이 입력 포트에 인접해서 큰 버퍼를 삽입해서 처음으 로 코어에 유입되는 신호를 한번 증폭시켜주기 위해서 이다.

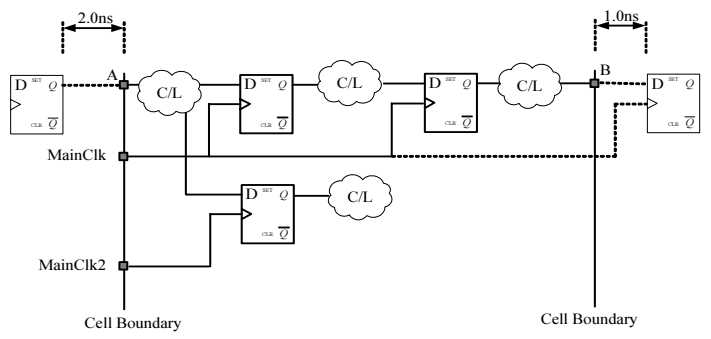

그림 5. 가상의 입출력 지연

Fig. 5 Virtual in/output delay

Astro에서 CTS와 HFNS(high fanout net synthesis)을 실시한다면 CTS 및 HFNS 대상 포트로부터 이들이 만 나는 첫 번째 순차까지의 경로에 버퍼, 인버터 등이 삽 입되어 있는 셀들을 지우게 된다. 경로에 이들이 있으 면 여러 가지로 문제가 발생할 수 있기 때문에 CTS 및 HFNS 경로는 어떤 셀도 삽입, 수정하지 말라는 속성 을 부여한다.

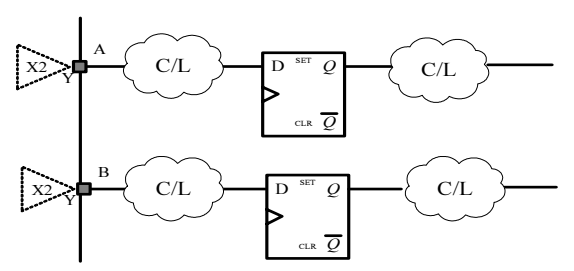

(a)

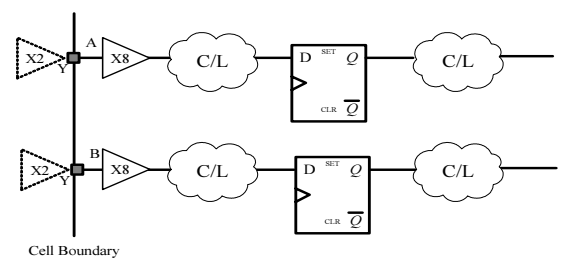

(b)

그림 6. 가상의 구동 셀 (a) 설정 전, (b) 설정 후

Fig. 6 Virtual driving cell (a) before, (b) after 
이 때문에 합성 후에는 CTS 및 HFNS 대상 포트는 그 림 7과 같이 대단히 많은 순차 셀을 한 번에 읽어 들이게 되고, 타이밍에 문제가 발생한다. 따라서 CTS 이전까지 는 이들 포트들은 대단히 큰 캐패시터 값을 가지므로 그 림 7과 같이 무한대의 셀을 구동 할 수 있다는 의미로 제 약조건을 적용시킨다.

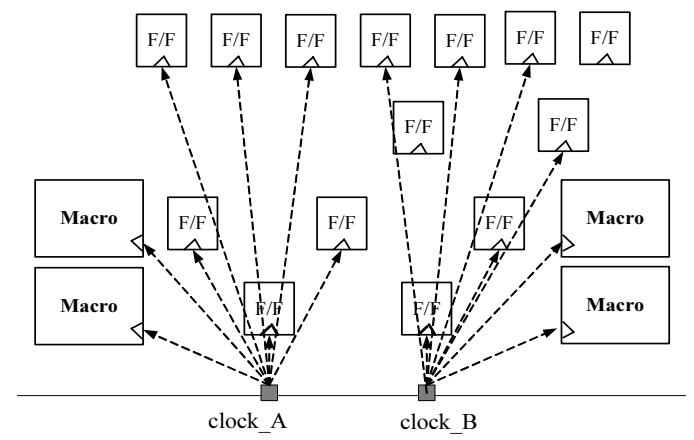

그림 7. 무한대의 구동력

Fig. 7 Infinite driving force

\section{6. 부하}

앞에서 입력 포트에 대한 구동 셀 설정은 Design Compiler가 입력 포트로 유입되는 신호의 구동력을 알 수 없기 때문에 이를 설계자가 설정해야 하기 때문이었 다. 이와 비슷하게 설계의 출력 포트에 달려있는 부하, 즉 R, C정보에 대해서 Design Dompiler는 알 수 없고, 설 계자만이 알 수 있다. 이를 알아야 설계의 내부에서 출 력 포트 외부의 부하를 보호할 수 있을 만큼의 구동력 을 갖도록 신호를 증폭시킬 수 있기 때문이다. 따라서 출력 포트의 외부의 전체 $\mathrm{R}$ 과 $\mathrm{C}$ 에 대한 정보와 출력 포 트의 부하 값이 등가라고 가정해야 한다. 이렇게 가정 한 값을 출력 포트에 제약조건 해주면 이를 구동할 수 있을 만큼의 셀을 출력 포트 근처에 삽입하거나크기를 조절해야 한다. 출력 부하의 설정 전후 회로를 그림 8 에 나타냈다.

지금까지 언급한 속성은 가장 일반적으로 사용되는 속성이다. 합성 시 필요한 속성은 무수히 많다. 합성도구 가 아무리 좋아도 설계자의 의도대로 합성 되지 않는다 면 결코 좋은 결과를 얻을 수 없다. 합성 및 배치\&배선 결과는 제약조건에 매우 종속적이므로 제약조건이 구 현 시 가장 중요하다고 할 수 있다.

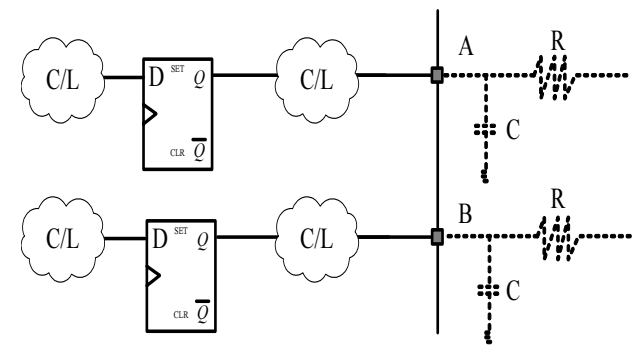

(a)

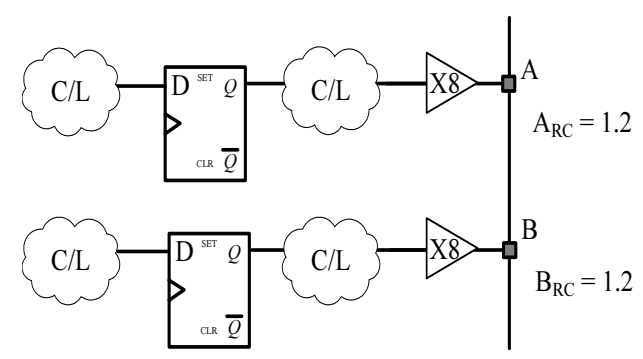

(b)

그림 8. 출력 부하 (a) 설정 전, (b) 설정 후 Fig. 8 Output load insertion (a) before (b) after

\section{III. 혼합 합성 방법}

아무리 합성을 위한 제약조건이 정확하다 하더라고 합성 방법이 잘못되었다면 좋은 결과를 얻을 수 없다. 합 성 방법은 계층을 어떻게 조합해서 합성을 수행하는지 에 따라서 크게 3 가지로 요약할 수 있다.

(1) 상향식(bottom-up) 방법 : 계층수준이 낮은 설계에서 부터 높은 순으로 합성을 수행하는 방법

(2) 하향식(top-down) 방법 : 계층수준이 높은 설계에서 부터 낮은 순으로 합성을 수행하는 방법

(3) 혼합(hybrid) 방법 : 계층을 일정규모로 분류해서 각 각은 상향식 방식으로 합성을 수행하고 이들의 결과 를 종합해서 다시 하향식 방식으로 합성을 수행하는 방법

그림 9에 몇 단계의 계층성을 갖는 설계를 보이고 있 는데 이를 예시로 설명하도록 한다. 


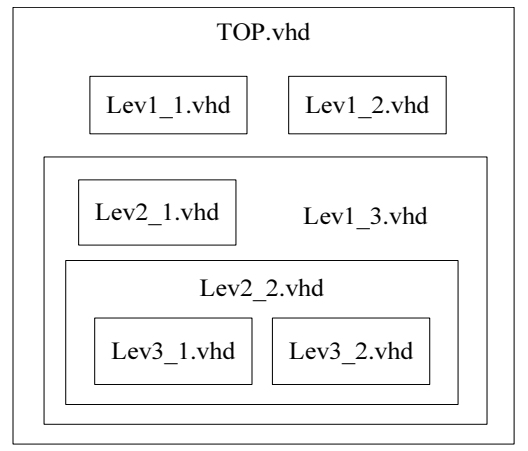

그림 9. 설계 예제

Fig. 9 Design example

그림 10 과 같이 상향식 방법은 계층이 낮은 순서대로 합성한 네트리스트들을 바로 위의 계층에서 읽어 들여 합하는 방법이다. 이 방법은 각각의 RTL을 따로 합성하 므로 메모리 사용율이 낮다. Design Compiler는 설계 내 타이밍, 면적이 중요한 부분(WNS:Worst Negative Slack) 부터 해결하고자 하는 특성이 있다. 만약 해결하지 못하 면 쉽게 해결할 수 있는 나머지 부분도 건드리지 않고합 성을 멈춘다. 따라서 설계 내에 중요한 부분이 없다면 좋 은 합성 효과를 볼 수 있다.

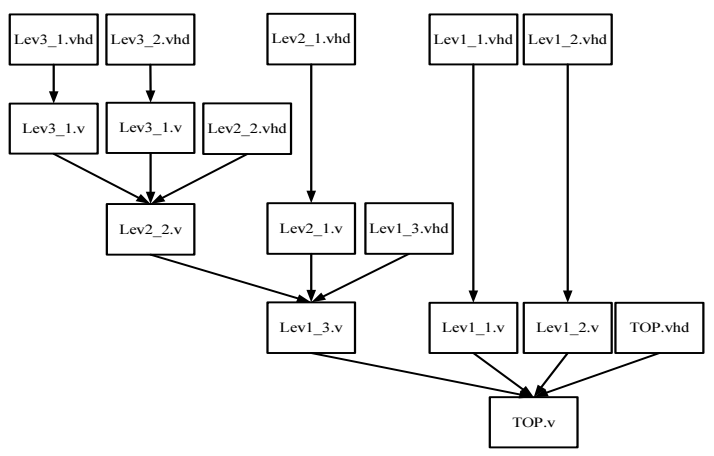

그림 10. 상향식 방법 Fig. 10 Bottom-up method

하향식 방법은 전체 설계의 전체 경로를 다루므로 중 요한 부분을 해결하다 보면 나머지 부분에 대해서는 다 소 소홀히 할 수가 있다. 그러나 상향식 방식은 임계경로 가 존재하는 설계를 제외하고 나머지는 최적화된 최적 화를 수행할 수 있다. 하위 블록부터 모든 블록에 대해서
각각 합성을 하기 때문이다. 이 점이 상향식의 최대 장점 이다. 그러나 합성 시간이 오래 걸리는 단점이 있다. 이 미 합성 해 놓은 설계를 계층이 높은 설계에서 파생해서 다시 합성하기 때문이다. 물론 이미 합성 되어있는 설계 는 변경금지(don't touch)를 수행할 수 있다. 그러나 설계 간 공유하고 있는 회로를 최적화해야 하기 때문에 이는 좋은 방법이 아니다.

최상위 설계에서 정의된 클록 이름이 하위 모듈에서 는 다르게 사상될 수 있다. 이때 하뒤 모듈만 분리해서 합성을 수행할 때 별도의 제약조건이 필요하게 된다. 하 향식 방식으로 합성을 수행한다면 최상위 설계에서 클 록 포트에 대해 정의해준 제약조건이 하위 모듈로 전파 되지만 하위 모듈만 분리하면 포트 이름이 다르므로 다 시 제약조건을 주어야 한다. 비단 클록 뿐 아니라 입력/ 출력 포트에 대한 지연시간도 마찬가지로 하뒤모듈에 맞도록 다시 정해주어야 한다.

그림 11 과 같이 하향식 방법은 계층에 관계없이 모든 $\mathrm{RTL}$ 을 읽어들여 최상위 설계의 입장에서 합성을 수행 하는 방법이다. 이는 상향식 방법에 비해 합성 수행속도 가 빠르다는 점이 최대의 장점이다. 또한 최상위 설계의 제약조건이 하뒤 모듈로 전파되므로 1 개의 제약조건만 있으면 된다. 그러나 상향식 방법과는 반대로 메모리 사 용율이 높고 임계경로가 존재할 경우 다른 설계까지 최 적화가 잘 안 된다는 단점이 있다.

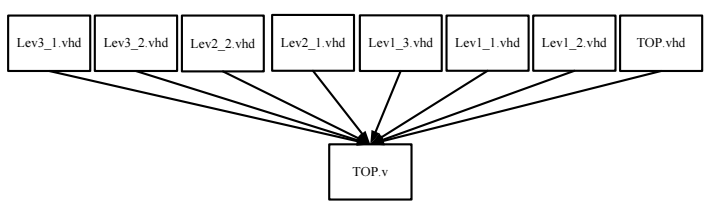

그림 11. 하향식 방법

Fig. 11 Top-down method

상향식 및 하향식 방법 중 한 가지만 고집하기 보다는 두 방법의 장점만 이용하는 혼합방법이 효과적이다. 이 어서 제안하고자 하는 혼합 방법을 그림 12 에 나타내었 다. 혼합방법은 일정규모의 설계를 모아서 하향식 방식 으로 합성하고 이들의 결과를 다시 모아서 합치는 방식 이다. 일반적으로 50 70만 게이트 정도를 하향식 방식 의 대상으로 한다. 이 방법은 너무 오래 걸리는 상향식 방법의 단점과 개별 설계의 최적화효과가 다소 떨어지 
는 하향식 방법의 단점을 극복할 수 있다. 물론 상향식 방법으로 합성되는 모듈은 제약조건을 다시 작성해야 한다.

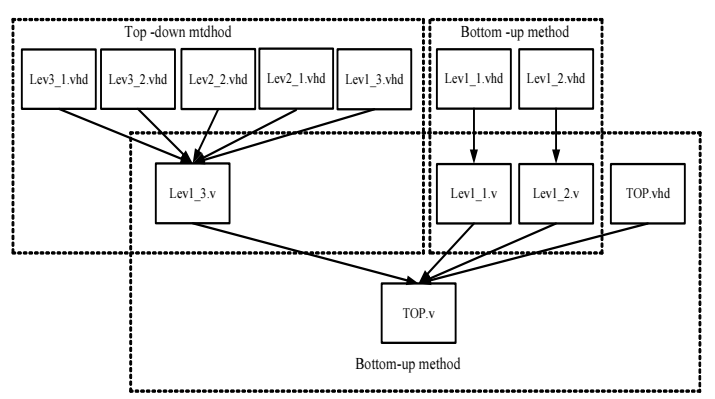

그림 12. 혼합방법

Fig. 12 Hybrid method

\section{IV. 실험 결과}

본 논문에서는 임의의 회로를 기준으로 하여 2 장에 서 고려한 합성 제약조건을 부여하고 3장에서 논의한 합성 방법들을 각각 적용하여 회로의 합성 결과를 분 석하였다.

하향식은 빠르지만 로컬 모듈에 시간적 이완(slack)이 발생하면 멈추게 된다. 상향식은 느리지만 로컬 모듈부 터 정밀하게 최적화를 수행할 수 있어 성능이 우수하다. 그러나 각 모듈의 제약조건을 만들어 주어야 하므로 작 업이 번거롭다. 따라서 빠르게 타이밍 결과를 한번 확인 한 후에 결과가 좋은 않은 로컬 모듈만 다시 합성하는 혼 합 방식을 사용하는 것이 적절하다. 표 1에는 H.264의 움 직임 추정기(motion estimation)를 설계한 회로의 합성 결 과를 나타내고 있다. 설계한 움직임 추정기는 $4 \times 4$ 크기 의 정합창으로 연산되면서 $8 \times 8$ 에서 $16 \times 16$ 의 정합창에 대한 $\mathrm{SAD}$ (sum of absolute difference) 결과를 병렬적으로 출력할 수 있는 구조를 갖고 있다. 세 가지 방법에 대해 서 게이트수, 합성 시간, 그리고 타이밍 결과를 나타냈 다. 세 가지 방법 모두 게이트수는 비슷한 결과를 보였 다. 합성 시간은 상향식 방법이 가장 오래 걸리고, 하향 식 방법이 가장 짧게 걸린다. 최적화 타이밍은 하향식이 가장 좋지 않다.
표 1. 합성 결과

Table. 1 Synthesis result

\begin{tabular}{|c|c|c|c|}
\hline & $\begin{array}{c}\text { Gate } \\
\text { Count }\end{array}$ & $\begin{array}{c}\text { Synthesis } \\
\text { Time }\end{array}$ & $\begin{array}{c}\text { Timing } \\
\text { (Optimization) }\end{array}$ \\
\hline \hline Bottom-up & 65,843 & 2시간 34분 & no slack \\
\hline Top-down & 65,301 & 1시간 22분 & $-12 \mathrm{ps}$ \\
\hline Hybrid & 65,512 & 1시간 53분 & no slack \\
\hline
\end{tabular}

\section{$\mathrm{V}$. 결 론}

본 논문에서는 논리합성을 위한 제약조건 방법과 효 율적인 논리합성방법에 대해서 제안하였다. 논리합성 을 위한 다양한 측면에서의 제약조건 특성에 대해서 설 명하였다. 그 중에서 클록의 선언, 불확실성, 잘못된 경 로, 입출력 포트의 지연, 구동 셀, 부하, 변경금지, 및 최 대 천이지연의 선언방법에 대해서 제안하였다. 합성 방 법에는 하향식 방법과 상향식 방법을 혼용한 혼합방법 에 대해서 제안하였다. 실제 회로에 이들을 적용하는 구체적인 예를 보였고, 합성 방법에 따른 회로의 합성 결과를 나타내었다. 따라서 혼합방법이 가장 효율적인 논리합성 결과를 보인다는 것을 확인하였다. 본 논문을 통해 논의된 제약조건에 대한 속성들과 논리합성 방법 들은 설계자들에 게 좋은 가이드라인이 될 것으로 사료 된다.

\section{참고문헌}

[1] Electronic Design Automation For Integrated Circuits Handbook, by Lavagno, Martin, and Scheffer, ISBN 0-8493-3096-3 A survey of the field of Electronic design automation. The above summary was derived, with permission, from Volume 2, Chapter 2, Logic Synthesis by Sunil Khatri and Narendra Shenoy.

[2] http://en.wikipedia.org/wiki/Logic_synthesis

[3] McGeer, P., J. Sanghavi, A. Sangiovanni-Vincentelli. Espresso-Signature: A New Exact Minimizer for Logic Functions. IEEE Transactions on VLSI, Vol. 1, No. 4, pp.432-440, 1993 
[4] Hlavička, J., P. Fišer. BOOM - A Heuristic Boolean Minimizer. Proc. International Conference on Computer Aided Design, pp. 439-442, 2001.

[ 5] McCluskey, E. Minimization of Boolean Functions. Bell System Technical Journal, pp. 1417-1444, NY, 1959.

[6] A Consistent Approach in Logic Synthesis for FPGA Architectures, by Burgun Luc, Greiner Alain, and Prado Lopes Eudes, Proceedings of the international Conference on Asic (ASICON), Pekin, October 1994, pp. $104-107$.

[7] G. D. Hachtel, F. Somenzi, "Logic Synthesis and Verification Algorithms", Kluwer Academic Pub., 1996.

[ 8 ] Brayton, R., et al. Logic Minimization Algorithms for VLSI Synthesis. Kluwer Academic Publishers, Boston, MA, 1984.

[9] Jie-Hong (Roland) Jiang, Srinivas Devadas (2009). "Logic synthesis in a nutshell". In Laung-Terng Wang, Yao-Wen Chang, Kwang-Ting Cheng. Electronic design automation: synthesis, verification, and test. Morgan Kaufmann. ISBN 9780123743640. chapter 6.

[10] Gary D. Hachtel; Fabio Somenzi (1996). Logic synthesis and verification algorithms. Springer. ISBN 0792397460. also as published as softcover ISBN 0387310045 in 2006

[11] Svoboda, A., D.E. White. Advanced Logical Circuit Design Techniques. Garland Press, New York, 1979.

[11] Roman Lysecky, Frank Vahid*, "On-Chip Logic Minimization”, DAC, Jun. 2003.

[12] Soha Hassoun, Tsutomu Sasao, ed (2002). Logic synthesis and verification. Kluwer. ISBN 978079 2376064.

\section{저자소개}

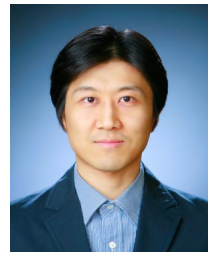

서영호(Young-Ho Seo)

1999년 2월 광운대학교 전자재료공학과 공학학사 2001년 2월 광운대학교 공학석사 2004년 8월 광운대학교 전자재료공학과 공학박사

2003년 6월 2004년 6월 한국전기연구원 연구원 2005년 9월 2008년 2월 한성대학교 조교수 2008년 3월 현재: 광운대학교 교양학부 부교수 ※관심분야 : realistic media, digital holography, realtime systems, SoC design, security

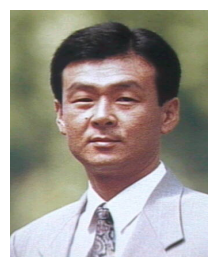

\section{김동욱(Dong-Wook Kim)}

1983년 2월 한양대학교

$$
\text { 전자공학과 공학학사 }
$$

1985년 2월 한양대학교 공학석사

1991년 9월 Georgia공과대학 전기공학과 공학박사

1992년 3월 현재 광운대학교 전자재료공학과 교수 ※관심분야: 디지털 VLSI Testability, VLSI CAD, 디지털 홀로그램, Wireless Communication 